\title{
Maternal and fetal outcome in preterm premature rupture of membrane
}

\section{Mamta Sharma*, Monika Agrwal, Hemavati Goudappagoudra}

\author{
Department of Obstetrics and Gynecology, Government Medical College, Kota, Rajasthan, India
}

Received: 03 August 2021

Revised: 25 September 2021

Accepted: 06 October 2021

\section{*Correspondence:}

Dr. Mamta Sharma,

E-mail: drmamtasharma08@gmail.com

Copyright: (c) the author(s), publisher and licensee Medip Academy. This is an open-access article distributed under the terms of the Creative Commons Attribution Non-Commercial License, which permits unrestricted non-commercial use, distribution, and reproduction in any medium, provided the original work is properly cited.

\begin{abstract}
Background: The objective was to study the maternal and fetal outcome in women with premature rupture of membranes.

Methods: It was a prospective analytic hospital based study, study population include 100 obstetrics cases of singleton pregnancy with gestational age of 28 week to 36 week with spontaneous rupture of membranes over a period of 2 years, 100 pregnant women without PROM upto 36 completed week taken as control. Detailed clinical examination of the patient was done to see any co-morbidity. Data was collected using a performa. Detailed workup including history, general physical examination, abdominal and pelvic examination and relevant specific investigation were noted.

Results: PROM occurs more frequently in primigravida compared to that of multigravida ( $\mathrm{p}=0.679$ ). Risk factors unknown factors $71 \%$ and history of coitus $5 \%$ UTI $(\mathrm{p}=0.001)$ which was highly significant, incidence of LSCS were found higher in PROM than in controls $(\mathrm{p}<0.05)$ which was statistically significant. Out of all vaginal deliveries, percentage of patients who had spontaneous labour were $69.86 \%$, while $30.14 \%$ were induced, $60 \%$ of cases was spontaneous out of which $51 \%$ delivered successfully vaginally and, $9 \%$ landed in cesarean section. $16 \%$ were given prostaglandin gel out of which $10 \%$ delivered successfully. $8 \%$ were augmented by oxytocin of which $6 \%$ delivered successfully and $2 \%$ landed in cesarean section. Out of 100 cases studies, $24 \%$ accounted for respiratory distress syndrome, while $6 \%$ in control group. $12 \%$ septicemia in study group $(\mathrm{p}=0.001)$ which was highly significant value, while conjunctivitis, neonatal jaundice (hyperbilirubinaemia) and intraventricular haemorrhage accounted for $2 \%, 3 \%$, and $2 \%$ each.

Conclusions: Present study concluded that most common cause of PPROM was unknown. Most common maternal morbidity was puerperal fever and neonatal morbidity was respiratory distress. Maternal and fetal morbidity increases with increase in duration between rupture of membranes and delivery of fetus, so augmentation of labour should be done.
\end{abstract}

Keywords: PPROM, Morbidity, Respiratory distress, Primigravida

\section{INTRODUCTION}

Preterm premature rupture of membranes (PPROM) is defined by Gibret and Harmon, in Year 2003. Premature rupture of membranes (PROM) is defined as rupture of fetal membranes before onset of labour. If it happens between 37 completed weeks and 42 weeks of gestational age, it is called term premature rupture of membranes (TPROM), while that occurring between 24 weeks and 37 weeks is called preterm premature rupture of membranes (PPROM). Rupture of membranes for $>24$ hours before delivery is called prolonged rupture of membranes. ${ }^{1}$

Premature rupture of membrane is common occurrence with an incidence of $5-10 \%$. It is a significant event as it cause maternal complications, increased operative procedures, neonatal morbidity and mortality. ${ }^{2}$ Preterm premature rupture of the membranes (PPROM) occurs in 
$3 \%$ of pregnancies and causes around $25-30 \%$ of all preterm deliveries. Since PPROM is associated with lower latency from membrane rupture until delivery, it is an important cause of perinatal morbidity and mortality. 3,4

During the latency period, the ascent of pathogenic microorganisms from the lower genital area could create complications such as intrauterine infections. Also, some studies introduced PROM as a pathologic process that often occurs following membrane inflammation and infection. ${ }^{5}$

However, one of the most common complications in PPROM patients is intrauterine infection, which can lead to chorioamnionitis, metritis after delivery and perinatal outcome such as neonatal sepsis. Other complications are cord compression leading to fetal distress, cord prolapse during rupture of membranes and placental abruption. Perinatal outcomes constitute prematurity, neonatal sepsis, respiratory distress syndrome (RDS), intraventricular hemorrhage (IVH), risk of fetal and neonatal death. ${ }^{6}$

For this study it has been defined as the spontaneous rupture of membranes during pregnancy beyond 28 weeks and before 37 completed weeks. The time from the rupture of membranes to the onset of contraction is defined as the latent period. The key factor in the fetal and maternal outcome is that the diagnosis of pre labour rupture of membranes must be established. In most instances either it is obvious from the release of clear amniotic fluid from cervix or by simple laboratory test like detection of fern pattern. The key to the management is an accurate assessment of gestational age and the presence or absence of sepsis. However the management is especially difficult in preterm patient in whom the risk of foetal and maternal infection that can accompany expectant treatment has to be weighed against potential improvement in neonatal outcome that comes with greater maturity of foetal lungs. ${ }^{7}$

Currently most authorities accept a plan of active management which includes prevention of infection, delay of delivery until foetal maturity is achieved, and active intervention by induction if labor is no longer preventable or if early infection is suspected. ${ }^{8}$

The aim of this study was to assess maternal and fetal outcome in women with premature rupture of membranes.

\section{METHODS}

\section{Study design}

This study was prospective, analytical hospital based study. The study was conducted in J. K. Lone, Mother and Child Hospital, Medical College, Kota.

\section{Study population}

The study population include 100 obstetrics cases of singleton pregnancy with gestational age of 28 weeks to 36 weeks with spontaneous rupture of membranes over a period of 2 years. The cases that fulfil the inclusion criteria was selected. The women who were fulfilling inclusion criteria were included in the study.

\section{Exclusion criteria}

Women with multiple pregnancy, gestational age $<28$ weeks and >36 weeks, pregnancy with any of medical disorder, cases with meconium stained liquor, faetal distress, intrauterine death, non-vertex presentation, artificial rupture of membranes and congenital malformations were excluded from the study.

\section{Control}

100 pregnant women without PROM upto 36 completed weeks are taken as control.

\section{Sampling technique}

Pregnant women with complain of leaking $>28$ and up to 36 week coming from antenatal, outdoor, emergency were admitted and were enrolled in the study.

Informed consent was taken. The cases fulfilling the inclusion criteria was taken for the study the cases was followed up to the delivery, and in the post natal ward till discharge. The study population was evaluated by detailed history and examination and predesigned proforma was filled for each patient.

\section{Procedure of study}

A detailed history was taken age, parity, menstrual and obstetric history with emphasis on exact time of rupture, duration, amount of leaking and association of pain, history of previous similar episodes in other pregnancies and history suggestive of incompetent os were evaluated.

Detailed history regarding recent coitus, severe physical exertion and vaginal examinations if any before admissions was noted. In general examination pulse, BP and temperature were noted followed by systemic examination in obstetric uterine height, presentation, position, lie of fetus and amount of liquor were noted. All parameters of maternal and fetal well-being were recorded.

A sterile speculum examination was conducted and presence of liquor amni was noted. When frank leaking was present litmus test performed. When no amniotic fluid was seen in the vagina, patient was asked to cough and per speculum done to see the drainage of amniotic fluid. In case of doubt fluid from vagina was collected on slide and examined under microscope for ferning. A single pelvic examination was done to note the Bishop's score presence or absence of membranes, presenting part and its station and to rule out cord prolapse and also pelvic assessment. All patients with leaking received prophylactic antibiotics. Thereafter the patient was monitored 4th hourly for signs 
of infections. A $4^{\text {th }}$ hourly monitoring of pulse, BP, temperature and presence or absence of contractions was made whenever required. The same was carried out more frequently. Fetal heart rate monitored regularly. Conservative management was done in all cases of PPROM for 24 hours provided there was no maternal or fetal indications for delivery. If patient did not go in labour they were induced with cerviprime gel and syntocinon for vaginal delivery. In cases of failed vaginal delivery or any complications caesarean section was done. Two doses of betamethasone $12 \mathrm{mg}$ i.m. 12 hours apart were given to mothers $<34$ weeks to enhance fetal lung maturity.

\section{RESULTS}

In present study majority belonged to 21-25 age group with in PROM patients and control group and maximum number of patients were unbooked. Maximum number of cases were primigravida $50 \%$ and $25 \%$ were second gravida.

Table 1: Risk factors for PROM.

\begin{tabular}{|llll|}
\hline Risk factor & Case & Control & P value \\
\hline Unknown & 71 & 0 & 0.001 \\
\hline History of recent coitus & 10 & 2 & $\chi^{2}=9.32$ \\
\hline $\begin{array}{l}\text { Previous history of } \\
\text { PROM }\end{array}$ & 5 & 3 & $\mathrm{~d} / \mathrm{f}=4$ \\
\hline Polyhydraminos & 9 & 4 & \\
\hline UTI & 5 & 1 & \\
\hline
\end{tabular}

Above Table 1 shows that $71 \%$ were unknown factors.

Table 2: Parity-wise distribution.

\begin{tabular}{|llll|}
\hline Parity & Case & Control & P value \\
\hline Primigravida & 50 & 52 & 0.679 \\
\hline Gravida-2 & 25 & 28 & $\chi^{2}=5.26$ \\
\hline Gravida-3 & 16 & 18 & $\mathrm{~d} / \mathrm{f}=3$ \\
\hline$\geq$ G-4 & 9 & 2 & \\
\hline Total & 100 & 100 & \\
\hline
\end{tabular}

$\left(\chi^{2}=5.26, p=0.679, d / f=3\right.$, not significant $)$

Above Table 2 shows that maximum number of cases $(50 \%)$ were primigravida and $25 \%$ were $2^{\text {nd }}$ gravida.

Table 3: Duration of leaking wise distribution of case.

\begin{tabular}{|lll|}
\hline $\begin{array}{l}\text { Duration of leaking } \\
\text { (hours) }\end{array}$ & No. of patients & Percentage \\
\hline $\mathbf{1 1 2}$ & 69 & 69 \\
\hline $\mathbf{1 2 - 2 4}$ & 23 & 23 \\
\hline $\mathbf{2 4}$ & 8 & 8 \\
\hline Total & 100 & 100 \\
\hline
\end{tabular}

Above Table 3 shows that in $69 \%$ women duration of leaking was $<12$ hours and in $8 \%$ women duration of leaking was $>24$ hours.
Table 4: Type of delivery wise distribution.

\begin{tabular}{|llll|}
\hline Mode of delivery & Case & Control & P value \\
\hline Vaginal delivery & 67 & 78 & 0.023 \\
\hline LSCS delivery & 33 & 22 & $\chi^{2}=8.36$ \\
\hline Total & 100 & 100 & $\mathrm{~d} / \mathrm{f}=1$ \\
\hline$\left(\chi^{2}=8.36, \mathrm{p}=0.023, \mathrm{~d} / \mathrm{f}=1\right.$, Significant $)$ & \\
\hline
\end{tabular}

Above Table 4 shows that out of 100 cases $67 \%$ delivered vaginally and $33 \%$ were LSCS.

Table 5: Neonatal morbidity.

\begin{tabular}{|llll|}
\hline $\begin{array}{l}\text { Neonatal morbidity } \\
\text { Respiratory distress }\end{array}$ & Case & Control & P value \\
syndrome & 24 & 6 & 0.001 \\
\hline $\begin{array}{l}\text { Septicemia and } \\
\text { pneumonia }\end{array}$ & 12 & 0 & $\chi^{2}=9.80$ \\
\hline Jaundice & 3 & 3 & $\mathrm{~d} / \mathrm{f}=4$ \\
\hline Conjunctivitis & 2 & 0 & \\
\hline $\begin{array}{l}\text { Intraventricular } \\
\text { hemorrhage }\end{array}$ & 2 & 0 & \\
\hline
\end{tabular}

$\left(\chi^{2}=9.80, p=0.001, d / f=4\right.$, Significant $)$

Above Table 5 shows that commonest neonatal mortality was respiratory distress syndrome.

Table 6: NICU admission.

\begin{tabular}{|c|c|c|c|c|}
\hline $\begin{array}{l}\text { NICU } \\
\text { admission }\end{array}$ & $\begin{array}{l}28-30 \\
\text { weeks }\end{array}$ & $\begin{array}{l}1-33 \\
\text { weeks }\end{array}$ & $\begin{array}{l}34-36 \\
\text { weeks }\end{array}$ & Total \\
\hline Case & 6 & 10 & 18 & 34 \\
\hline Control & 4 & 6 & 8 & 18 \\
\hline P value & 0.001 & $\chi^{2}=8.94$ & $\mathrm{~d} / \mathrm{f}=2$ & \\
\hline
\end{tabular}

Above Table 6 shows that maximum number of NICU admission in cases as well as control group were in gestational age 34-36 weeks.

\section{DISCUSSION}

Premature rupture of membranes is fairly a common complication of pregnancy and can lead to increased maternal complications, operative procedures, neonatal morbidity and mortality the present study was undertaken to identify risk factors causing PROM and to study labor outcome maternal morbidity and perinatal morbidity and mortality associated with PPROM.

In our study it is evident that $62 \%$ are unknown factors of PPROM and history of coitus 5\%, 4\% UTI. Findings correlate with the study of Patil et al with unknown factors by $59 \%$ and history of coitus $10 \%$, UTI $6 \%$ as a cause of PPROM. ${ }^{9}$

Our study shows $50 \%$ of PPROM case were primi and $25 \% 2^{\text {nd }}$ gravida, $16 \% 3^{\text {rd }}$ gravida. It shows that PROM occurs more frequently in primigravida compared to that 
of multigravida. This could be explained on the basis of less married life and more frequency of coitus, causing ascending infections and UTI, prostaglandin production causing direct toxic effect on membranes. Our study is comparable with the study of Jameela et al. ${ }^{10}$

Our study shows that $69 \%$ women of PPROM leaking time was less than 12 hours. $23 \%$ from $12-24$ hours and $8 \%>24$ hours. This could be explained on the basis that most of the patient were unbooked and they reported to the concerned $\mathrm{CHC}$ or PHC early and were referred to higher center immediately due to lack of NICU facility. Our findings are comparable with the study of Shailaja et al. ${ }^{11}$

Our study shows that percentage of vaginal deliveries was $67 \%$ compared to LSCS which is $33 \%$. LSCS was done more in cases where duration of leaking was more than 12 hrs. Cases with less than 12 hours of leaking were delivered vaginally. Findings are comparable with the study of Patil et al. ${ }^{9}$

In our study $69.86 \%$ were delivered vaginally spontaneously, while $13.69 \%$ were induced with cerviprime gel, $8.21 \%$ induced with syntocinon. Patil et al showed $19 \%$ spontaneous vaginal delivery and $17.8 \%$ induced by cerviprime gel while Minakeshi et al show $66 \%$ spontaneous vaginal delivery and $34 \%$ induced with cerviprime gel. ${ }^{9,12}$ Our study is comparable with the study of Patil et al and Minakeshi et al., ${ }^{9,12}$

Our study shows that out of 100 cases, $24 \%$ accounted for respiratory distress syndrome, $12 \%$ septicemia. Our study is comparable with study of Patil et al and Padma et al. ${ }^{9,13}$ Our results were lower than Patil et al and Padma et al. This could be explained on the basis as $72 \%$ cases were enrolled between 34-36 weeks of gestational age and small sample size.

Present study shows out of 100 cases each in the study and control group, $34 \%$ were admitted in NICU which is comparable with the study of Patil et al where NICU admission was 36\%.9 Our study shows less NICU admission compared with the study of Hassan et al $(65.3 \%) .{ }^{14}$ This could be explained on the basis of timely decision of $\mathrm{c}$ section for fetal distress, placental abruption and failed progress.

\section{CONCLUSION}

Present study concluded that most common cause of PPROM was unknown. Most common maternal morbidity was puerperal fever and neonatal morbidity was respiratory distress. Maternal and fetal morbidity increases with increase in duration between rupture of membranes and delivery of fetus, so augmentation of labour should be done. In our study most common cause of cesarean was previous cesarean. Number of neonatal death were more in newborn weighing less than $1.5 \mathrm{~kg}$ this could be because of prematurity than PPROM per se.
Funding: No funding sources

Conflict of interest: None declared

Ethical approval: The study was approved by the Institutional Ethics Committee

\section{REFERENCES}

1. Simhan HN, Canvan TP. Preterm premature rupture of membranes; diagnosis, evaluation and management strategies. BJOG. 2005;112:32

2. Denney MJ, Cuhane FJ, Goldenberg LR. Prevention of preterm birth. Women Health. 2008;4:625-38.

3. Morris JM, Roberts CL, Crowther CA, Buchanan S1, Henderson Smart DJ, Salkeld G. Protocol for the immediate delivery versus expectant care of woman with preterm prelaboure rupture of the membranes close to term (PPROMT) trail. BMC Pregnancy Childbirth. 2006;6:9.

4. Smith G, Rafuse C, Anand N, Brenanan B, Connors $\mathrm{G}$, Crane J, et al. Prevalence, management and outcomes of preterm prelabour rupture of the membranes of women in Canada. J Obstet Gynecol Can. 2005;27:547-53.

5. Tahir S, Aleem M, Aziz R. Incidence and outcome of preterm premature rupture of membranes. Pak J Med Sci. 2002;18(1):26-32.

6. Ghazi A, Jabbar S, Siddiq MH. Preterm labour- still a challenge. Pak J Surg. 2006;22:222-6.

7. Charles PJ, Muriel R, Charles PJ, Rene E, Olivien C, Pascal G, et al. A prospective population based study of 598 causes of PROM between 24 and 34 weeks gestation description management and morality (Dominos Cohort). Eur J Obstet Gyreacol Reprod Biol. 2005;121:164-70.

8. Al QaQa K, Awaysheh FA. Neonatal outcome and prenatal antibiotics treatment in premature rupture of membranes. Pak J Med Sci. 2005;21:441-4.

9. Patil S, Patil V. Maternal and foetal outcome in premature rupture of membranes. IOSR J Dent Med Sci. 2014;13(12):56-81.

10. Diraviyam JMV, Karunakaran L. Maternal and perinatal outcome in pretermpremature rupture of membranes. Int J Reprod Contracept Obstet Gynecol. 2017;6:2498-502.

11. Surayapalem S, Cooly V, Salicheemala B. A study on maternal and perinatal outcome in premature rupture of membranes at term. Int J Reprod Contracept Obstet Gynecol. 2017;6:5368-72.

12. Kayiga H, Lester F, Amuge PM, Byamugisha J, Autry AM. Impact of mode of delivery on pregnancy outcomes in women with premature rupture of membranes after 28 weeks of gestation in a lowresource setting: a prospective cohort study. PLoS One. 2018;13(1):e0190388.

13. Choudhari P, Chhabra S, Kiyawat V. Evaluation of results of titanium elastic nailing system in paediatric lower extremity fractures of long bones. J Evol Med Dent Sci. 2014;3(72):15303-10. 
14. Boskabadi H, Maamouri G, Mafinejad S. Neonatal complications related with prolonged rupture of membranes. Maced J Med Sci. 2011;4(1):93-8.
Cite this article as: Sharma M, Agrwal M, Goudappagoudra H. Maternal and fetal outcome in preterm premature rupture of membrane. Int J Reprod Contracept Obstet Gynecol 2021;10:4178-82. 